\title{
SENSITIZATION TO AEROALLERGENS IN PEDIATRIC PATIENTS WITH ALLERGIC RHINITIS AND ASTHMA
}

\section{Nikolay K. Balgaranov, Lachezar S. Nikolov, Nadia I. Kolarova-Yaneva, Vania N. Nedkova, Kristina Ts. Tabakova, Viktor E. Donev}

Department of Pediatrics, Medical University - Pleven, Bulgaria

\section{Corresponding Author:}

Nikolay Balgaranov

Department of Pediatrics, University Hospital - Pleven

8a, Georgi Kochev Blvd.

Pleven, 5800

Bulgaria

e-mail:balgaranov2@abv.bg

Received: December 06, 2016

Revision received: December 18, 2016

Accepted: December 20, 2016

\section{Summary}

Asthma and allergic rhinitis are common in childhood. Establishing sensitization to aeroallergens is crucial to effectively prevent exacerbation of these respiratory allergic diseases. The study aimed to evaluate sensitization to the most common aeroallergens in children with asthma and allergic rhinitis. We established a correlation between patients sensitized to indoor, outdoor and simultaneously to both allergens. The study population consisted of 276 patients (168 boys and 108 girls) ages 4 to 16 years with asthma (A) and allergic rhinitis (AR). Skin prick tests were performed with 21 commercial allergen extracts: pollens, mites, epithelia and insects, and molds. We found that 217 patients were sensitized to at least one aeroallergen: 117 patients had a positive result to mites, 92 to pollens, 72 to epithelia and insects, and 63 - to mold allergens. Dermatophagoides pteronyssinus was the most prevalent aeroallergen. Sensitized only to indoor allergens were 104 patients, 60 only to outdoor allergens, and 53 were sensitized to both. Mites were the most frequent aeroallergens in children with A and AR. Lately there has been found a significant increase in rates of sensitization to mold allergens, especially to Alternaria alternata. Our study has confirmed the dominant role of indoor allergens in children with respiratory allergic diseases.

Key words: sensitization, allergens, child, asthma in children, allergic rhinitis

\section{Introduction}

Numerous published studies have reported that prevalence rates of asthma (A) and allergic rhinitis (AR) in children have increased over the last two or three decades [1-3]. It is estimated that, worldwide, between $1 \%$ and $20 \%$ of the children and young adults have A, and around $20 \%$ of individuals (all age groups) have AR [4, 5]. In this context, identification of aeroallergen sensitization in the early stages of life is of great importance for the diagnosis and treatment of respiratory allergic diseases. This identification makes it possible to start a specific treatment and modify the natural 
history of the allergic disease [6]. In order to correctly diagnose respiratory allergies, it is useful for allergists to know the most important inhalant allergens in different countries, as the allergens vary in distribution, depending on the region. At the same time, mobility is increasing all over the world and allergists face consulting patients from other countries. Despite of the fact that IgE-specific allergen sensitivity in children with A and AR can be easily proven, childhood sensitization rates are underreported.

Skin prick test (SPT) is the standard for the diagnosis of IgE-mediated allergic diseases. It is a safe, simple and inexpensive method that provides results quickly [7].

The aim of this study was to evaluate sensitization rates of the most common aeroallergens in children with $\mathrm{A}$ and AR. In addition, we expected to establish a correlation between patients sensitized to indoor, outdoor and to both indoor and outdoor allergens.

The present study focused only on sensitization and did not explore the clinical relevance of the sensitization, i.e. the link between sensitization to a specific allergen and symptoms.

\section{Materials and Methods}

The study included 276 patients (168 boys and 108 girls) aged between 4 and 16 years (mean 8.163.33). Of them, $117(42.39 \%)$ were with moderate and severe persistent AR, and 159 (57.61\%) - with well and partly controlled A. In this latter group, 96 asthmatics (60.38\%) presented with symptoms of AR simultaneously. The diagnosis and classification of diseases were based on international consensuses: Allergic Rhinitis and its Impact on Asthma, 2010 Revision (ARIA), and Global Initiative for Asthma, Updated 2013 (GINA) [8,9].

The study population consisted of patients from Bulgaria (Southeast European country) referred to the pediatric allergy center between October 2013 and November 2015. We performed SPT with 21 commercial allergen extracts (Stallergens, Alyostal prick, Antony, France), divided in following 4 groups:

A. Pollens:

- weeds: Ambrosia elatior, Artemisia vulgaris, Medicago sativa, Urtica dioica, Plantago, Chenopodiaceae;

- grasses: 12 grasses, 4 cereals;

- trees: Betulaceae, Fegaceae, Salycaceae;
B. Mites: Dermatophagoides pteronyssimus ( $D$. pt) and Dermatophagoides farinae (D.f.);

C. Epithelia and insects: cat, dog, feathers mixture (duck, goose, hen), cockroach;

D. Molds: Alternaria alternata, Aspergillus mix, Cladosporium mix, Penicillium mix.

In addition, based on their origin and place of predominant influence, these 21 allergens were divided into two subgroups:

- outdoor allergens: pollens and molds with predominantly outdoor distribution Alternaria alternata and Cladosporium mix;

- indoor allergens: mites, epithelia and insects, molds with predominantly indoor distribution: Aspergillus mix and Penicillium mix.

A histamine positive control and a glycerol negative control were also skin tested to reduce false positives and negatives. The positive data of previous ingestion of antihistamines were considered exclusion criteria for the test.

The size of SPT was determined after 20 minutes by summing the largest wheal diameter and its perpendicular, and dividing the result by two. The mean wheal diameter (MWD) was qualified in relation to the negative control. An MWD of at least $3 \mathrm{~mm}$ greater than the negative control was considered positive.

\section{Statistical analysis}

The data from the survey was processed with the statistical software package SPSS 19 and Microsoft Excel.

\section{Results}

Skin prick testing showed that 217 out of 276 patients $(78.62 \%)$ with A and AR had at least one positive result to investigated aeroallergens. In other $59(21.38 \%)$ all SPTs were negative (Figure $1)$.

In addition, sensitization to allergens from one group was found in 150 patients (69.12\%) with positive SPT, to allergens from two groups in 40 patients $(18.43 \%)$, to allergens from three groups -23 patients $(10.60 \%)$ and only in 4 cases $(1.84 \%)$ - to allergens from all four investigated groups of allergens (Figure 2). 


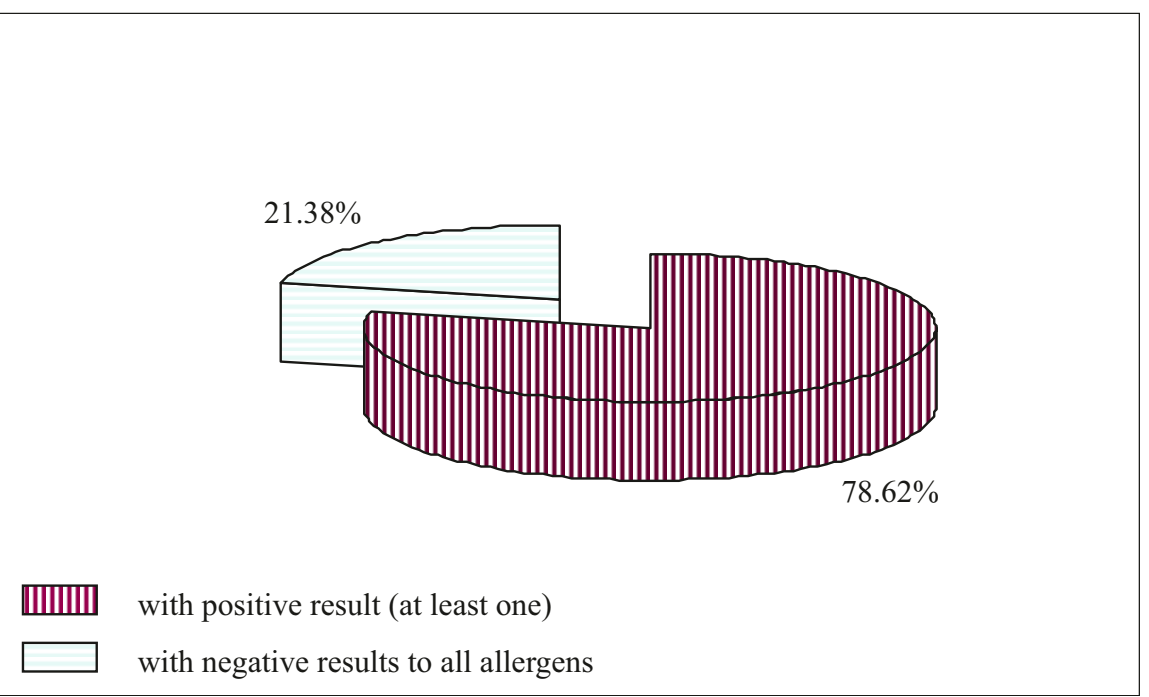

Figure 1. Sensitization to aeroallergens in children with asthma and allergic rhinitis

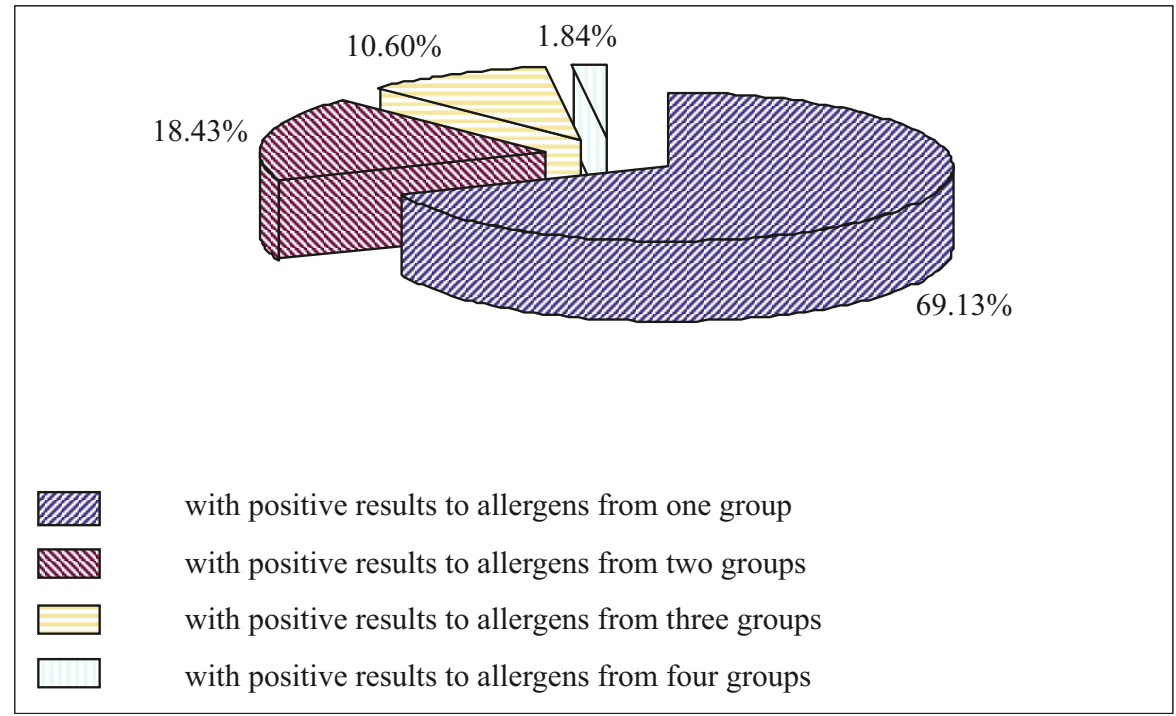

Figure 2. Distribution of patients depending on the number of groups of allergens to which a positive SPT result was established

Sensitization rates to allergens of the investigated groups are shown in Table 1.

In 62 patients out of 92 with positive results to pollens, we established sensitization to grasses $(67.39 \%)$, in $46(50.00 \%)$ - to weeds, and in 18 $(19.57 \%)$-sensitization to trees (Figure 3 ).

In 117 children, SPTs were positive to allergens of mites. Moreover, in 65 patients (55.56\% of cases in this group), the SPTs were positive to $D$. pt. and D.f. simultaneously, in 34 (29.06\%) - only to D. pt., and other $18(15.38 \%)$ were with positive result only to $D . f$. (Figure 4).

Positive results to aeroallergens from the group of epithelia and insects were found in 72 cases. Rates of sensitization to allergens from cat and dog were equal -39 out of $72(54.17 \%)$. In 22 children, the SPTs were positive to allergens of cockroach $(30.56 \%)$ and only in $8(11.11 \%)$ - to feathers mixture (Figure 5).

In 63 children, the SPTs were positive to allergens of molds. In this group, sensitization to Alternaria alternata was found in 48 cases (76.19\%), to Cladosporium mix in $16(25.40 \%)$, to Aspergillus mix - in 17 cases $(26.98 \%)$, and finally to Penicillium mix - in 11 cases $(17.46 \%)$ (Figure 6).

The structure of sensitization to aeroallergens based on their origin and predominant influence is shown in Table 2. 
Table 1. Sensitization to the groups of allergens in children with asthma and allergic rhinitis

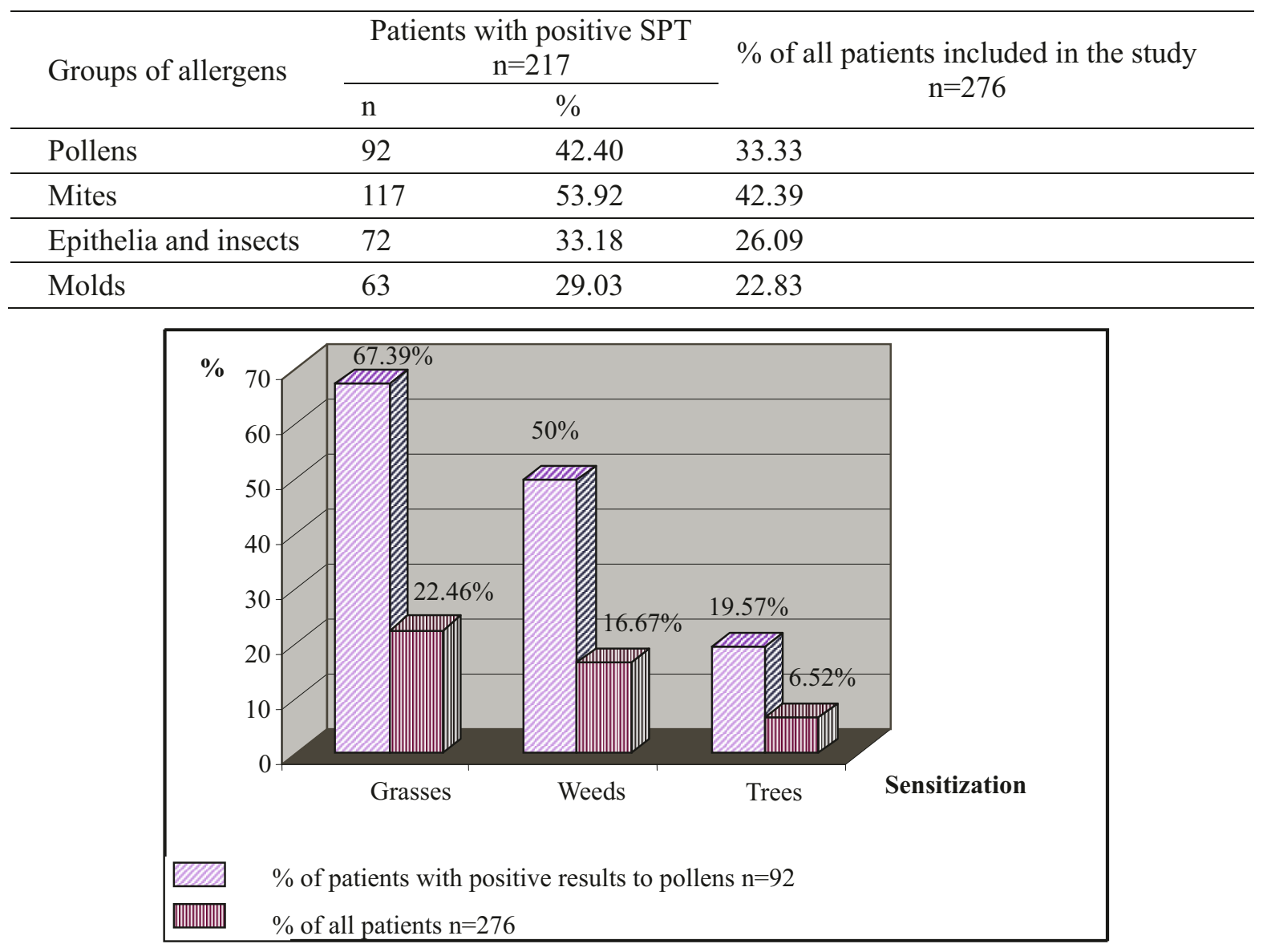

Figure 3. Sensitization to pollens in children with asthma and allergic rhinitis

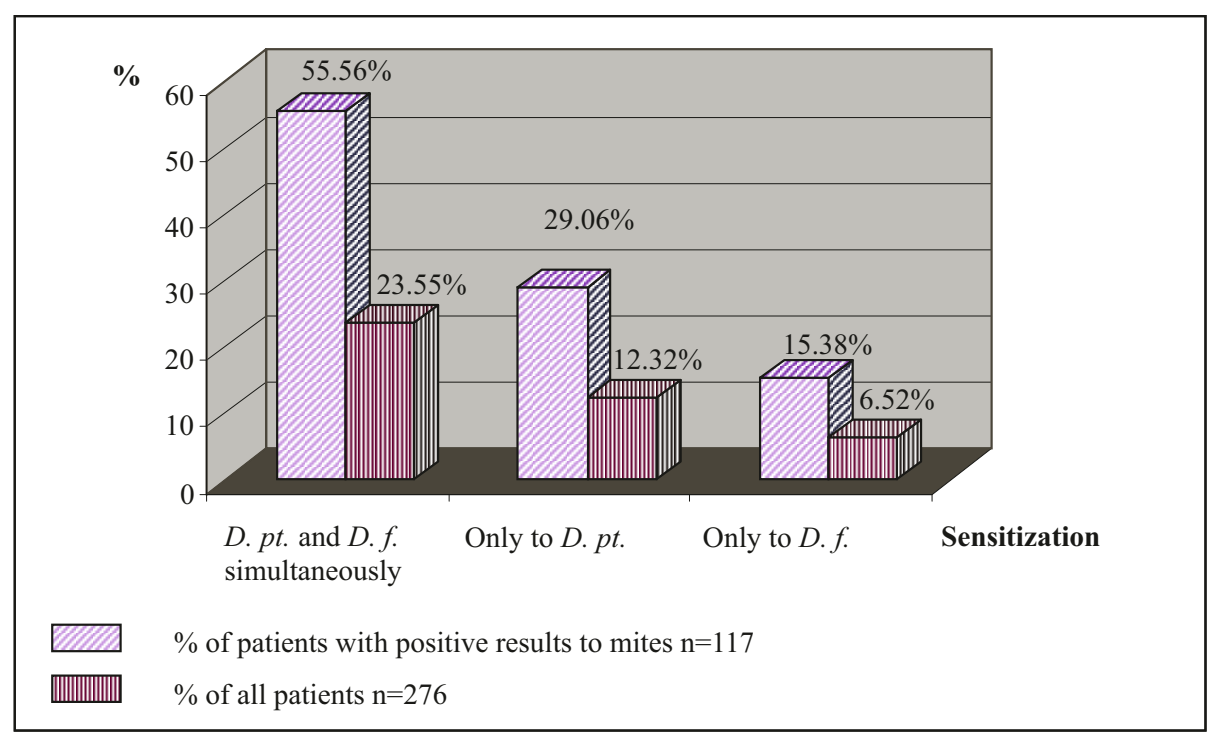

Figure 4. Sensitization to mites in children with asthma and allergic rhinitis 


\section{Discussion}

A relatively high percent of children with A and AR $(78.62 \%)$ were with positive results of SPTs. That is why this method should be strongly recommended to patients, who are suspected for atopic character of the disease. As was expected, allergens of the mites were the most frequent established - in $42.39 \%$. Many patients (23.55\%) were sensitized to $D$. $p t$. and D.f. simultaneously, which was probably the consequence of the cross reactivity. Sensitization to $D$. pt. only, was twice more prevalent than the one to $D . f .-12.32 \%$ and $6.52 \%$, respectively. That is why $D$. pt. was the most prevalent aeroallergen, to which we found positive results $(\mathrm{n}=99 ; 35.87 \%)$. Our data on the impact of D. pt. and D.f. in children with A and $\mathrm{AR}$ are similar to these obtained in a multicentre international European study involving 3034 subjects with allergic respiratory diseases [10].

Sensitization to grasses was the most prevalent among pollens $(22.46 \%)$. However, the prevalence of sensitization to trees $(6.52 \%)$ and weeds $(16.67 \%)$ were lower than expected. This is probably the due to the differences in age of the tested population and specific vegetation and climate factors in any particular country [11].

Sensitization to allergens from the group of epithelia and insects differ considerably from rates established in elder patients. We found positive SPTs to allergens of cat $(14.13 \%)$, dog $(14.13 \%)$, feathers mixture $(2.90 \%)$ and cockroach with a lower frequency, as compared to that in adults [12-14].

Approximately 80 fungus species have been reported to be connected with respiratory allergy. Moreover, it is proven that four of them are the most common: Alternaria, Aspergillus, Cladosporium and Penicillium [15]. They belong to the taxonomy group fungi imperfecti (usually Ascomycetes). Alternaria and Cladosporium species are common in outdoor environments worldwide. Their airborne spores and mycelium debris present during spring, summer and especially autumn because of the degradation of leaves and other biomaterial [16]. In indoor environments, Aspergillus and Penicillium species predominate with relatively few characteristic seasonal changes $[17,18]$. Despite of the fact that the presence of IgE-specific mold sensitivity is proven, childhood sensitization rates in Europe are underreported. It appears, however, that sensitization to mold allergens in children from our region has increased, according to the results we found, as compared to these published ten years ago [19]. This is especially true for Alternaria alternata (17.39\%) the frequency of sensitization to which proved to be in the fourth place after D. pt. $(35.87 \%), D$. f. $(30.07 \%)$, and grasses $(22.46 \%)$. The total frequency of sensitization to the other three mold allergens was lower than the one found to Alternaria: Aspergillus mix (6.16\%), Cladosporium mix (5.80\%) and Penicillium mix (3.99\%).

In our study, patients were most often sensitized only to indoor allergens $(37.68 \%)$. This sensitization correlates well with indoor allergen exposure in young and school-age children [20-23]. It has been found that adults in the US spend an average $87 \%$ of their time indoors [24]. Infants and toddlers are likely spend even more time indoors between home and daycare, and are frequently in close proximity to settled household dust, which contains these allergens [25]. The sensitization only to outdoor aeroallergens we established was considerably less - in $21.74 \%$ of the patients investigated. In other $19.20 \%$ of the patients, SPTs were positive to indoor and outdoor allergens simultaneously.

\section{Conclusions}

Mites were the most frequent aeroallergens established by SPT in children with A and AR. In recent years the rates of sensitization to mold allergens, especially to Alternaria alternata have increased significantly. The present study again proves the dominant role of indoor allergens in children with respiratory allergic diseases. SPT is a highly effective, safe and time-effective method and should be recommended for children with A and AR.

\section{References}

1. Lundbäck B. Epidemilogy of rhinitis and asthma. Clin Exp Allergy. 1998;28(Suppl 2):3-10.

2. Gupta R, Sheikh A, Strachan DP, Anderson HR. Time trends in allergic disorders in the UK. Thorax. 2007;62(1):91-6.

3. de Marco R, Cappa V, Accordini S, Rava M, Antonicelli L, Bortolami O, et al. Trends in the prevalence of asthma and allergic rhinitis in Italy between 1991 and 2010. Eur Respir J. 2012;(39):883-92.

4. Asher MI, Keil U, Anderson HR, Beasley R, Crane J, Martinez F, et al. International study of 
asthma and allergies inchildhood (ISAAC): Rationale and methods. Eur Respir J. 1995;(8):483-91.

5. Begin P, Nadeau KC. Epidemic regulation of asthma and allergic disease. Allergy Asthma Clin Immunol. 2014;10:27.

6. Sharma HP, Hausel NN, Matsui L, Diette GB, Eggleston P, Breysse P. Indoor environmental influences on children's asthma. Pediatr Clin North Am. 2007;(54):103-20.

7. Wood RA. Skin testing: making the most of every prick. Allergy Asthma Clin Immunol. 2002;(88):347-9.

8. Brozek JL, Bousquet J, Baena-Cagnani CE, Bonini S, Canonica GW, Casale TB, et al. Allergic Rhinitis and Its Impact on Asthma (ARIA) guidelines. J Allergy Clin Immunol. 2010;126(3):466-76.

9. Global Initiative for Asthma (GINA). Global strategy for asthma management and prevention [Internet]. Global Initiative for Asthma [updated 2013 Dec; cited 2014 Feb). Available from: www.ginasthma.org.

10. Bousquet PJ, Burbach J, Heizerling LM, Edenharter G, Bachert C, Bindslev-Jensen C. GA(2)LEN skin test study III: Minimum battery of test inhalant allergens needed in epidemiological studies in patients. J Allergy Clin Immunol. 2009:(64):1656-62.

11. Marinho S, Simpson A, Söderström L, Woodcock A, Ahlstedt S, Custovic A. Quantification of atopy and the probability of rhinitis in preschool children: a population-based birth cohort study. $\mathrm{J}$ Allergy Clin Immunol. 2007;(62):1379-86.

2. Huss K, Adkinson NF Jr, Eggleston PA, Dawson C, Van Natta ML, Hamilton RG. House dust mite and cockroach exposure are strong risk factors for positive allergy skin test responses in Childhood Asthma Management Program.J Allergy Clin Immunol. 2001;107(1):48-54.

13. Boulet LP, Turcotte H, Laprise C, Lavertu C, Bé dard PM, Lavoie A, et al. Comparative degree and type of sensitization to common indoor and outdoor allergens in subjects with allergic rhinitis and/or asthma. Clin Exp Allergy. 1997;27(1):52-9.

14. Bousquet PJ, Chatzi L, Jarvis D, Burney P. Assessing skin prick tests reliability in ECRHS-I. J Allergy Clin Immunol. 2008;(63):341-6.

15. medscape.com [Internet]. American Academy of Allergy Asthma and Immunology; 2015 [updated: 2015 Aug 27; cited 2015 Dec 29]. Mold allergy; [about 4 screens]. Available from: www.emedicine.medscape.com/article/887374.2 015 .

16. Cecchi I, D'Amato G, Ayres JG, Galan C, Forastiere F, Forsberg B. Projections of the effects of climate change on allergic asthma: the contribution of aerobiology. J Allergy Clin Immunol. 2010;65(9):1073-1081.

17. Heinzerling L, Frew AJ, Bindslev-Jensen C, Bonini S, Bousquet J, Bresciani M, et al. Standard skin prick testing and sensitization to inhalant allergens across Europe - a survey from the GALEN network. J Allergy Clin Immunol. 2005;60(10):1287-1300.

18. Manning SC, Vuitch F, Weiberg AG, Brown OE. Allergic aspergillosis: a newly recognized form of sinusitis in the pediatric population. The Laryngoscope. 1989; 99(7):7681-85.

19. Antova T, Pattenden S, Brunekreef B, Heinrich J, Rudnai P, Forastiere F, et al. Exposure to indoor mould and children's respiratory health in the PATY study. J Epidemiol Community Health. 2008;62(8):708-14.

20. Gruchalla RS, Pongracic J, Plaut M, Evans R 3rd, Visness CM, Walter M, et al. Inner City Asthma Study: relationships among sensitivity, allergen exposure, and asthma morbidity. J Allergy Clin Immunol. 2005;(115):478-85.

21. Torrent M, Sunyer J, Garcia R, Harris J, Iturriaga MV, Puig C, et al. Early-life allergen exposure and atopy, asthma, and wheeze up to 6 years of age. Am J Respir Crit Care Med. 2007;(176):446-53.

22. Torrent M, Sunyer J, Munoz L, Cullinan P, Iturriaga MV, Figueroa $\mathrm{C}$, et al. Early-life domestic aeroallergen exposure and $\mathrm{IgE}$ sensitization at age 4 years. J Allergy Clin Immunol. 2006;(118):742-8.

23. Phipatanakul W, Celedon JC, Hoffman EB, Abdulkerim H, Ryan LM, Gold DR. Mouse allergen exposure wheeze and atopy in the first seven years of life. J Allergy Clin Immunol. 2008;63(11):1512-8.

24. Klepeis NE, Nelson WC, Ott WR, Robinson JP, Tsang AM, Switzer P, et al. The National Human Activity Pattern Survey (NHAPS): a resource for assessing exposure to environmental pollutants. J Expo Sci Environ Epidemiol. 2001;(11):231-52.

25. Arbes SJ, Sever M, Mentha J, Collette N, Thomas B, Zeldin DC. Exposure to indoor allergens in daycare facilities: results from 2 North Carolina counties. J Allergy Clin Immunol. 2005;(116):133-9. 